\title{
Study of the Dynamic Response of Polymer-Matrix Composites Using an Innovative Hydraulic Crash Machine
}

\author{
Walid Harizi $^{1}$ - Sami Kaidi ${ }^{1}$ Aurélie Monnin ${ }^{1}$ - Nemr El Hajj ${ }^{1}$ Zoheir Aboura $^{1}$ • \\ Malk Benzeggagh ${ }^{1}$
}

Received: 3 July 2015/Accepted: 15 September 2015/Published online: 23 September 2015

(C) Society for Experimental Mechanics, Inc 2015

\begin{abstract}
This paper describes the design and implementation of a new innovative machine for hydraulic crash of composite materials. Polymer-matrix composite (PMC) plates with polyamide 11 (PA11) matrix/woven glass fibers were impacted with the new machine at 10 bars during $5 \mathrm{~ms}$ and their dynamic response, in terms of crash pressure and deflection at the pole, was evaluated respectively by two pressure transducers and a laser system. During the hydraulic crash test generating a shock wave within a metal enclosure, PMC plates undergo a tensile/compressive loading cycles which produce a damped vibration following the viscous aspect of the thermoplastic resin PA11. In view of the anisotropy and heterogeneity of composite materials, a numerical simulation with ABAQUS code has been proposed for predicting the dynamic behavior of PMC plates during the pressure rise phase of a proposed hydraulic crash cycle. Numerical deflection at the pole and the stresses field are investigated and compared with the experimental study. The obtained results show a very interesting potential of this machine for studying the dynamic behavior of composite structures under low-velocity impact test.
\end{abstract}

Keywords Polymer-matrix composites (PMCs) · Woven fabrics - New machine - Hydraulic crash - Impact test . Dynamic response

Walid Harizi

walid.harizi@gmail.com; walid.harizi@utc.fr

1 Sorbonne Universités, Université de Technologie de Compiègne, CNRS, Laboratoire de Mécanique Roberval UMR 7337, Dept GM, CS 60319, 60203 Compiègne Cedex, France

\section{Introduction}

Different types of composite materials have recently been introduced and studied in different scales from macro to nanocomposites. Cross-ply polymer-matrix composite (PMC) laminates are strongly used in various fields because they are lightweight materials, resistant to corrosive environments and exhibiting remarkable mechanical and physical properties [1-6].

Even though they display interesting mechanical properties, thermosetting polymer matrices also present undeniable drawbacks: low-temperature storage, very long curing process, and hand-made draping, which cause most of the irreversible defects during the manufacturing process. Thereby, high performance thermoplastic resins offer a promising alternative to thermosetting resins. Indeed, semi-crystalline thermoplastic resins offer a number of advantages over conventional thermosetting resins (such as epoxies): a high degree of chemical resistance, excellent damage and impact resistances, and they may be used over a wide range of temperatures. Following an impact, PMC laminates may undergo delamination, resulting in low damage tolerance, which is of great concern for aircraft applications [7, 8].

Low velocity impact is one of the most detrimental solicitations for composite laminates because it drastically reduces the residual mechanical properties of the structure [9-12]. During an impact solicitation, a large structure will experiment a very large range of strains and strain rates (possibly very high levels at the impact point and time, and possibly very low levels far from this point and time). To obtain mechanical tests for all these strain rates, from static to dynamic cases, different testing machines have to be used because it is not possible to easily design a single testing machine of such mechanical capabilities that are 
required by the targeted tests. Alternatively, finding hydraulic machines that can still develop such efforts dynamically is almost impossible. Today, one can more easily find commercial conventional testing machines for strain rates lower than $0.1 \mathrm{~s}^{-1}$, servo-hydraulic machines for strain rates between 0.1 and $100 \mathrm{~s}^{-1}$ [13-21] and split Hopkinson pressure bars (SHPB) for strain rates from 500 to $10^{4} \mathrm{~s}^{-1}$, which can be used to test metallic and composite materials [22-26]. Very high strain rates from $10^{4}$ to $10^{6} \mathrm{~s}^{-1}$ can be achieved using the acceleration of projectiles or the detonation of explosives to generate shock waves [22].

The dynamic tests raised major difficulties in view of their goal which was to perform tests at a constant and imposed strain rate. Also, the same problem was posed in the characterization of out-of-plane and through-thethickness material properties. Indeed, for composite materials it is necessary to manufacture very thick plates to be able to machine test specimens to study the materials out of-plane tension, compression and shear properties [26]. The current development of composite (especially high modulus and toughness GFRP and CFRP) materials with higher mechanical characteristics is bringing the difficulty back in the test laboratories (especially when 3D interlock, braided, stitched sandwich, etc., composite materials are studied). For these reasons, specimens with added tabs, and dog-bones forms, were also sometimes used for tension or compression dynamic tests respectively. Being destructives, the related costs of dynamic tests are very high (one must also consider that for research needs, the instrumentation and the results exploitation are heavy and expensive processes).

Several mechanical parts may be subjected to a crash during their service. In the case of fluid tanks made with thermoplastic composite material and upon crash (tank/soil contact), the fluid filling the tank has a major contribution in the total failure of structure as it is impacting its internal walls. Thus, it is a fluid/solid contact, denoted hydraulic crash. In contrast, none of the classical impact methods is able to investigate the mechanical behavior in this crash configuration since there is no fluid in the impact operation. The originality of this study lies in particular in the design and establishment of a new innovative hydraulic crash machine. Composite plates with polyamide 11 (PA11) thermoplastic resin and woven glass fibers are then tested and their dynamic response is analyzed in terms of crash pressure and maximum deflection at the pole during the hydraulic crash test conducted at ten bars. A numerical simulation of the pressure rise phase of crash test was established under ABAQUS code through explicit dynamic finite element method (FEM).

This paper presents the goal and design of the new hydraulic crash machine in "Brief Theoretical Background of the New Hydraulic Crash Machine" section, and the first experimental and numerical results obtained on thermoplastic composite specimens with glass fiber-reinforced PA11 resin in both "Dynamic Crash Test and Experimental Procedures" and "Results and Discussion" sections.

\section{Brief Theoretical Background of the New Hydraulic Crash Machine}

The new innovative hydraulic crash machine is illustrated in Fig. 1 with a 3D representation and its general dimensions are summarized in Table 1. Its principal aim is the study of the deformability of materials following a hydraulic crash using water. It can be used for several purposes: safety check, destructive tests to find the limit pressure and limit deflection of composite panels, verification of bonding joints and tightness or determination of the off-plan displacement field. Its operation and different parts have been presented before in Ref. [27]. The overall drawing of the new machine is shown in Fig. 2. A metal mass (3) (net weight of $750 \mathrm{~kg}$ ) is connected by magnets to a mechanical system (string/sprocket) which promotes its translational guidance along the $\mathrm{Z}$ axis. In free fall, the mass (3), equipped with a mechanical cam (4) at the end of its side surface, generates a translational movement along the $\mathrm{X}$ axis of a hydraulic jack (5) which pushes water

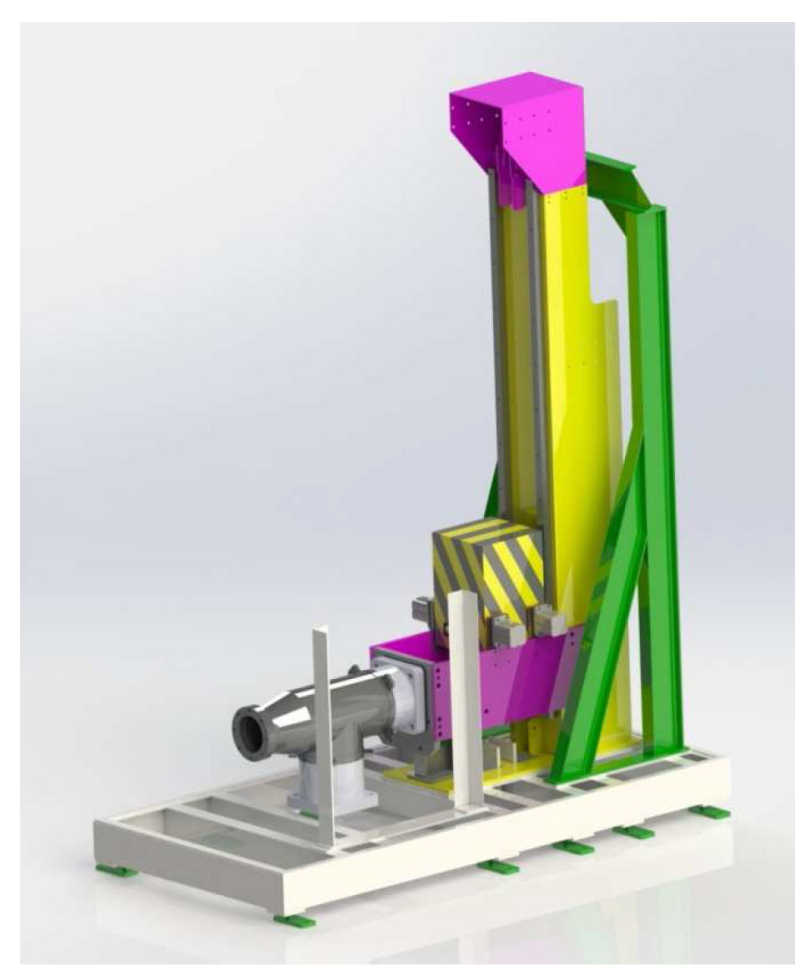

Fig. 1 A 3D representation of hydraulic crash machine 
Table 1 General data of the new hydraulic crash machine

\begin{tabular}{lc}
\hline Designation & Values \\
\hline Length (mm) & 3000 \\
Height (mm) & 3820 \\
Width (mm) & 1500 \\
Electrical voltage (Volt) & 380 \\
Weight (tons) & 2 \\
\hline
\end{tabular}

(assumed incompressible) that comes impacting the composite plate embedded at the end of the enclosure.

Energy conservation principle written during the free fall of the mass (3) between two positions A and B placed at heights $z_{A}$ and $z_{B}$ respectively (Fig. 2), gives Eq. (1).

$\frac{1}{2} m_{(3)} V_{A}^{2}+m_{(3)} g z_{A}=\frac{1}{2} m_{(3)} V_{B}^{2}+m_{(3)} g z_{B}$

where $m_{(3)}$ is the net weight of part (3). We note that $V_{A}=0$ (zero speed at the moment of the fall) and $z_{B}=0$ [when the mass (3) is based on the damping springs (7)], the crash velocity transmitted from the component (3) to the hydraulic jack (5) along $\mathrm{X}$ axis can be estimated by Eq. (2):

$V_{B}=\sqrt{2 g z_{A}}$

This new machine allows studying a crash response of circular structures (monolithic or sandwich panels) with a varying thickness and a wide range of impact velocities by varying the free fall height of the mass or the stroke of hydraulic jack [27].

\section{Dynamic Crash Test and Experimental Procedures}

\section{Material}

The composite material used in this study is a woven-ply glass fiber-reinforced semi-crystalline thermoplastic resin, PA11. Thermoplastic resin is presented in film form with a thickness of $125 \mu \mathrm{m}$ (from Arkema, France). The characteristics of PA11 are summarized in Table 2. However, the used twill $2 / 2$ fabric is from "Porcher Composites" with E glass type. The density of E glass filament is $2.54 \mathrm{~g} / \mathrm{cm}^{3}$ with a diameter $9 \mu \mathrm{m}$. The total number of filaments in the warp of glass fabric is 2112. In the representation of the weave pattern in column 5 of Table 3 , warp yarns are shown by a black color whereas white color is attributed to weft yarns.

The manufacturing method chosen was the compression molding process by thermo-stamping:

It is performed using a stamping press which exerts a maximum closing pressure $\mathrm{P}_{\max }=35$ bars between two heating trays. Composite plate should have a thickness of $3 \mathrm{~mm}$ and a fiber volume fraction of $40 \%$. The required plies number of twill fabric in glass fiber is 8 . Each ply is placed between two sheets of PA11. In total, 16 sheets are used with a symmetrical stacking to avoid the appearance of residual stresses. During the compression process, vacuum is maintained in order to evacuate the air trapped within the stacking, ensuring a low rate of voids in the composite plate at the end of manufacturing cycle. The processing temperature was fixed at $220{ }^{\circ} \mathrm{C}$. Compression time was optimized experimentally and was set at $25 \mathrm{~min}$. The cooling rate of the two heating trays was fixed at $5{ }^{\circ} \mathrm{C} /$ min and demoulding was carried out at $30^{\circ} \mathrm{C}$.

Three composite specimens provided for hydraulic crash are cut from the same GFRP plate by water jet, they have an average diameter of $\varnothing=230 \pm 1 \mathrm{~mm}$ and a mean thickness of $3 \pm 0.1 \mathrm{~mm}$ (Fig. 3a). Having three samples from the same thermoplastic plate reduces the variability of test results and allows a reproducible dynamic behavior. Their static elastic mechanical properties obtained at $2 \mathrm{~mm} / \mathrm{min}$ and physical properties are summarized in Table 4 (average values). In this study, to simulate the real behavior of an aeronautic tank, an elastomeric membrane in film form with a thickness of $3 \mathrm{~mm}$ (Fig. 3b) is used with the composite specimen. This membrane serves as a container of fluid but the composite panel plays the box role. In general, the elastomeric membrane remains intact even after the crash of the box. Mechanical and physical properties of the elastomeric membrane are presented in Table 5. After fixing and clamping at the end of the metal enclosure, the useful impacted diameter for composite and elastomeric specimens is only $190 \mathrm{~mm}$.

\section{Hydraulic Crash Test}

The new machine is used to study the mechanical behavior of composite structures during a hydraulic crash (fluid/solid contact). In this study, we want to lead the hydraulic crash test at ten bars during a time period of $10 \mathrm{~ms}$. The rise at the maximum pressure (ten bars) is to be performed for a time which does not exceed $5 \mathrm{~ms}$ (Fig. 4). The composite specimen and the elastomeric membrane are separated by a seal with a thickness of $3 \mathrm{~mm}$. The membrane is brought into contact with the fluid used for the shock test whereas the composite sample is outer side. The metal mass (3) is placed at a height $z_{A}=660 \mathrm{~mm}$ (Fig. 2). In total, three samples were tested according to the hydraulic crash cycle shown in Fig. 4.

Two pressure transducers TP1R of ten bars (AEP transducers, with a nominal sensitivity $2 \mathrm{mV} / \mathrm{V}$ and a maximum permissible pressure of $150 \%$ ) are located on two sides of the metal enclosure, one in the right and another in the left, just before reaching the composite plate of few centimeters (Fig. 5a). Hydraulic crash machine is 


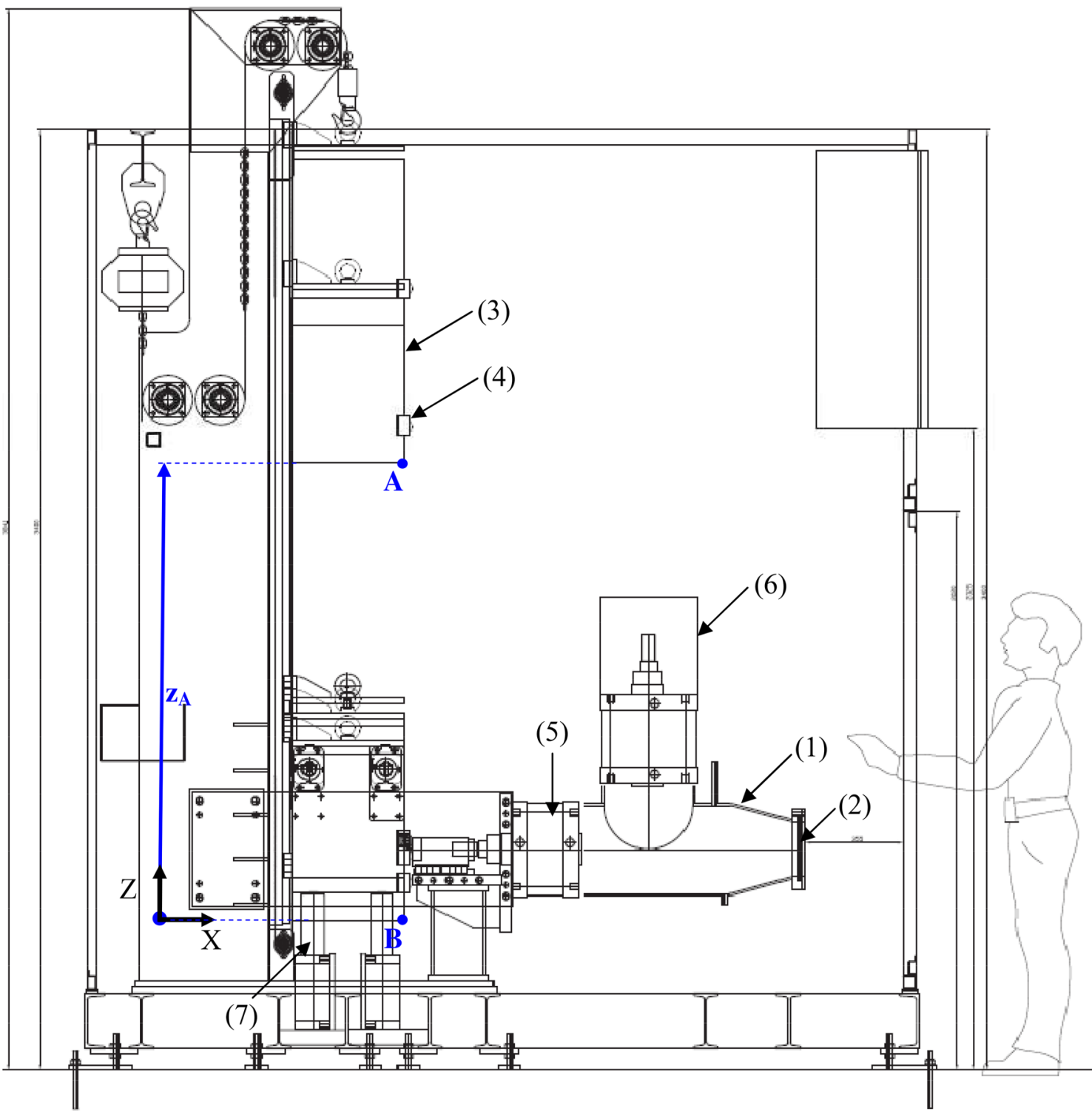

(1) Metal enclosure

(2) Tested material

(3) Metal mass

(4) Mechanical cam

(5) Hydraulic jack

(6) Pneumatic chamber

(7) Damping springs

Fig. 2 Overall drawing

Table 2 Characteristics of PA11 resin

\begin{tabular}{lr}
\hline Designation & Values \\
\hline Melt temperature $\left({ }^{\circ} \mathrm{C}\right)$ & 185 \\
Glass transition temperature $\left({ }^{\circ} \mathrm{C}\right)$ & 42 \\
Young's modulus $(\mathrm{MPa})$ & 1500 \\
\hline
\end{tabular}

instrumented with a laser system (M70LL/200) to measure the deflection of composite plate at its center. The distance between the laser and the composite plate is $335 \mathrm{~mm}$. A fast camera (model FASTCAM SA 1.1 of "Photron", with a maximum speed of 5457 frames per second at a full resolution of 1 mega pixel $(1024 \times 1024))$ is used to film the fast crash scene (Fig. 5b). 
Table 3 Characteristics of yarns used in the manufacturing of the twill $2 / 2$ fabric

\begin{tabular}{|c|c|c|c|c|c|c|c|c|c|}
\hline \multirow[t]{2}{*}{ Product } & \multicolumn{2}{|l|}{ Yarn type } & \multirow{2}{*}{$\begin{array}{l}\text { Weight } \\
\left(\mathrm{g} / \mathrm{m}^{2}\right)\end{array}$} & \multirow[t]{2}{*}{ Weave Pattern } & \multirow[t]{2}{*}{ Sizing } & \multicolumn{2}{|c|}{ Nominal texture } & \multicolumn{2}{|c|}{ Mass distribution } \\
\hline & Warp & Weft & & & & $\begin{array}{l}\text { Warp } \\
(\text { yarn/cm) }\end{array}$ & $\begin{array}{l}\text { Weft } \\
\text { (counts/cm) }\end{array}$ & $\begin{array}{l}\text { Warp } \\
(\%)\end{array}$ & $\begin{array}{l}\text { Weft } \\
(\%)\end{array}$ \\
\hline E glass fabric & EC9 $68 \times 5$ t0 $(340$ tex $)$ & EC9 273 & 399 & Twill 2/2 & K506 & 6.0 & 6.6 & 53 & 47 \\
\hline
\end{tabular}

Fig. 3 Composite (a) and elastomeric (b) specimens used in hydraulic crash test

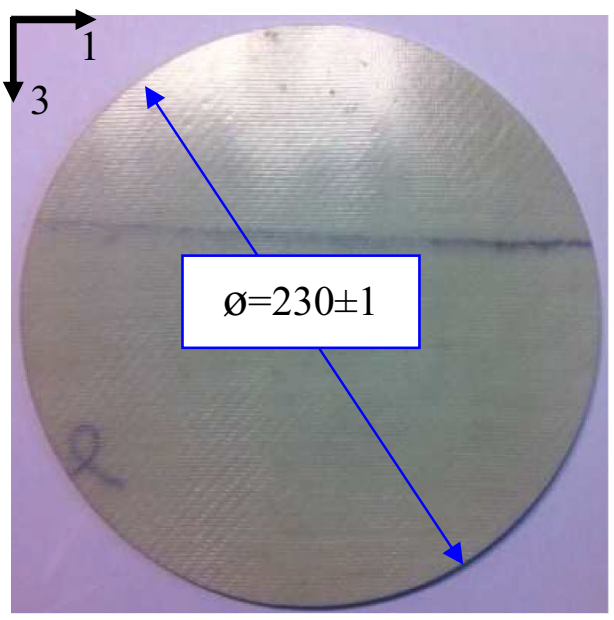

(a)

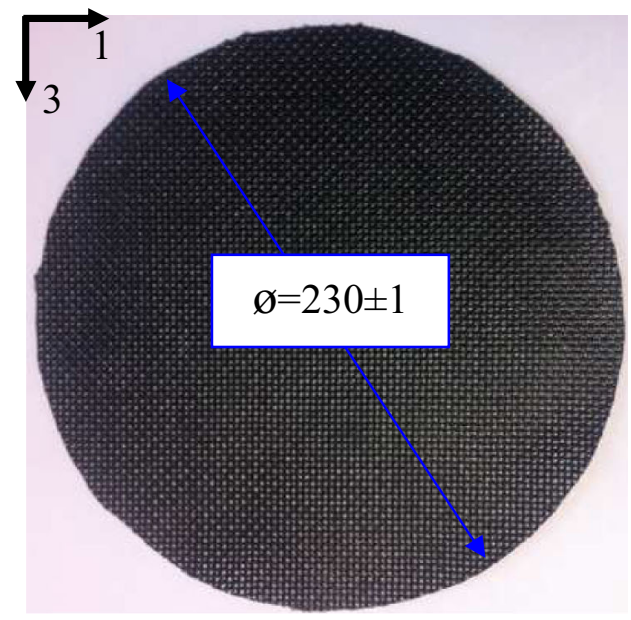

(b)

Table 4 Mean values of elastic mechanical and physical properties of PA11/glass fibers composite material

\begin{tabular}{lllllllllll}
\hline $\mathrm{E}_{1}(\mathrm{MPa})$ & $\mathrm{E}_{2}(\mathrm{MPa})$ & $\mathrm{E}_{3}(\mathrm{MPa})$ & $v_{12}$ & $v_{13}$ & $v_{23}$ & $\mathrm{G}_{12}(\mathrm{MPa})$ & $\mathrm{G}_{13}(\mathrm{MPa})$ & $\mathrm{G}_{23}(\mathrm{MPa})$ & Yield stress $(\mathrm{MPa})$ & Density $\left(\mathrm{g} / \mathrm{cm}^{3}\right)$ \\
\hline 16,600 & 10,000 & 16,600 & 0.3 & 0.1 & 0.3 & 2000 & 2200 & 2000 & 287 & 1.73 \\
\hline
\end{tabular}

Table 5 Mechanical propertied and density of elastomeric membrane

\begin{tabular}{lc}
\hline Designation & Values \\
\hline Young's modulus $(\mathrm{MPa})$ & 71 \\
Poisson's ratio & 0.5 \\
Density $\left(\mathrm{g} / \mathrm{cm}^{3}\right)$ & 0.99 \\
\hline
\end{tabular}

The results obtained during the crash tests conducted at ten bars will be presented as an average form determined on the basis of the three thermoplastic composite specimens tested in this study to obtain an average typical behavior.

\section{Results and Discussion}

\section{Crash Pressures and Deflection at the Pole}

The typical pressures (right and left) recorded by the two pressure transducers are shown in Fig. 6. They have the same variation and reach ten bars just during $5.1 \mathrm{~ms}$. The total cycle duration including the load climb and descent can be estimated at $10 \mathrm{~ms}$. These results prove that the imposed cycle shown in Fig. 4 is well respected. The rise and descent of the crash pressure are not smooth and present fluctuations. This is due to the dynamic of the crash. Similarly, it should be noted that after undergoing the 


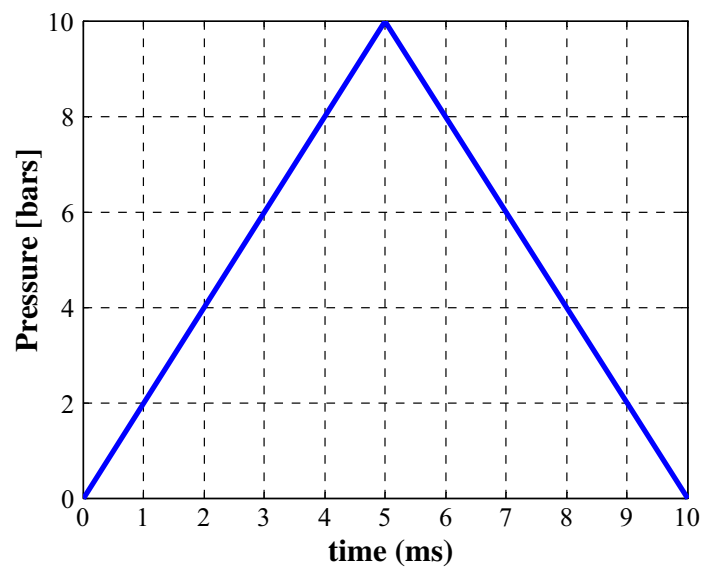

Fig. 4 Hydraulic crash cycle

impact at ten bars, PA11/glass fibers composite plate presents a "spring" effect resulting from tensile (positive pressure) and compression (negative pressure) phases.

Typical deflection of PA11/glass fibers plate measured in its center by the laser system is shown in Fig. 7. The maximum deflection recorded is $12.55 \mathrm{~mm}$, corresponding at the maximum pressure of ten bars with an offset of $1.2 \mathrm{~ms}$ because the two pressure sensors detect the shock wave before the latter reaches the composite plate. After, according to its "spring" effect, the plate deforms and oscillates in positive and negative senses up to find its equilibrium position. The measured deflection at the pole varies from $-12.55 \mathrm{~mm}$ to $+3.81 \mathrm{~mm}$, reaching $-4.78 \mathrm{~mm}$ at $203 \mathrm{~ms},+2 \mathrm{~mm}$ at $209.7 \mathrm{~ms},-3 \mathrm{~mm}$ at $217.4 \mathrm{~ms}$, +0.54 at $224 \mathrm{~ms},-2.25 \mathrm{~mm}$ at $232 \mathrm{~ms}$ and finally $-0.15 \mathrm{~mm}(\approx 0)$ at $238.5 \mathrm{~ms}$ (Fig. 7). Based on both Figs. 6 and 7, the solicitation rate of composite plate can be evaluated at $2.28 \mathrm{~m} / \mathrm{s}$ (deflection of $12.55 \mathrm{~mm}$ during $5.5 \mathrm{~ms}$ ). The crash velocity $V_{B}$ transmitted from the part (3) to the hydraulic jack (5) along $\mathrm{X}$ axis can be evaluated by Eq. (2) to $3.6 \mathrm{~m} / \mathrm{s}$ using $z_{A}=660 \mathrm{~mm}$. For this reason, the crash pressure increase shown in Fig. 6 begins from

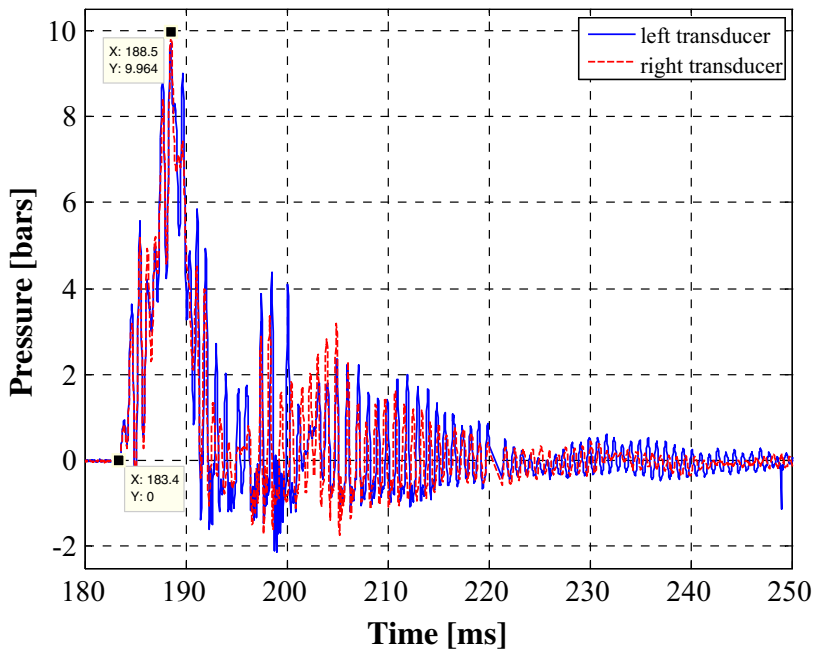

Fig. 6 Typical behavior of PA11/glass fibers composite material under a hydraulic crash test conducted at ten bars

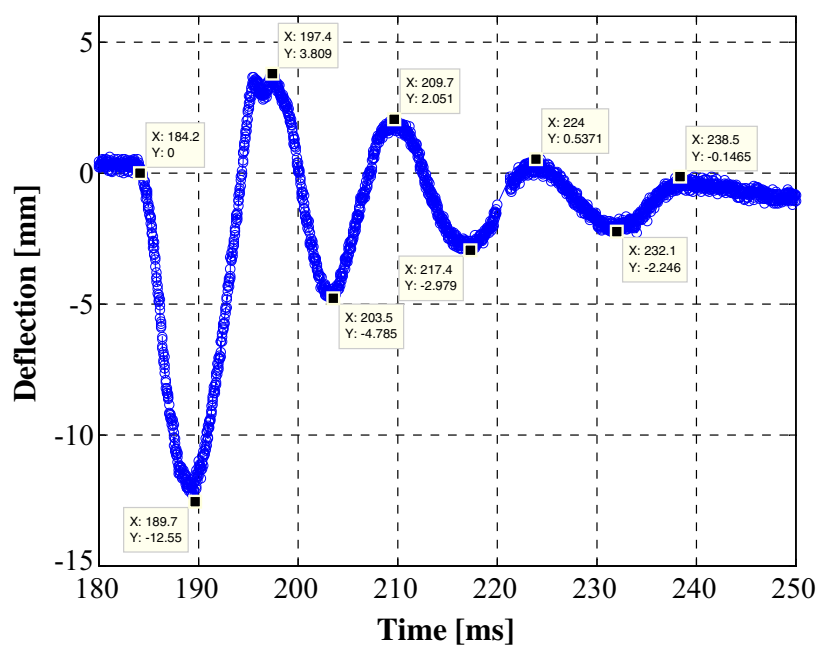

Fig. 7 Typical deflection of PA11/glass fibers composite material under a hydraulic crash test a ten bars
Fig. 5 Instrumentation of the crash machine with two pressure transducers (a), a laser system and a fast camera (b)
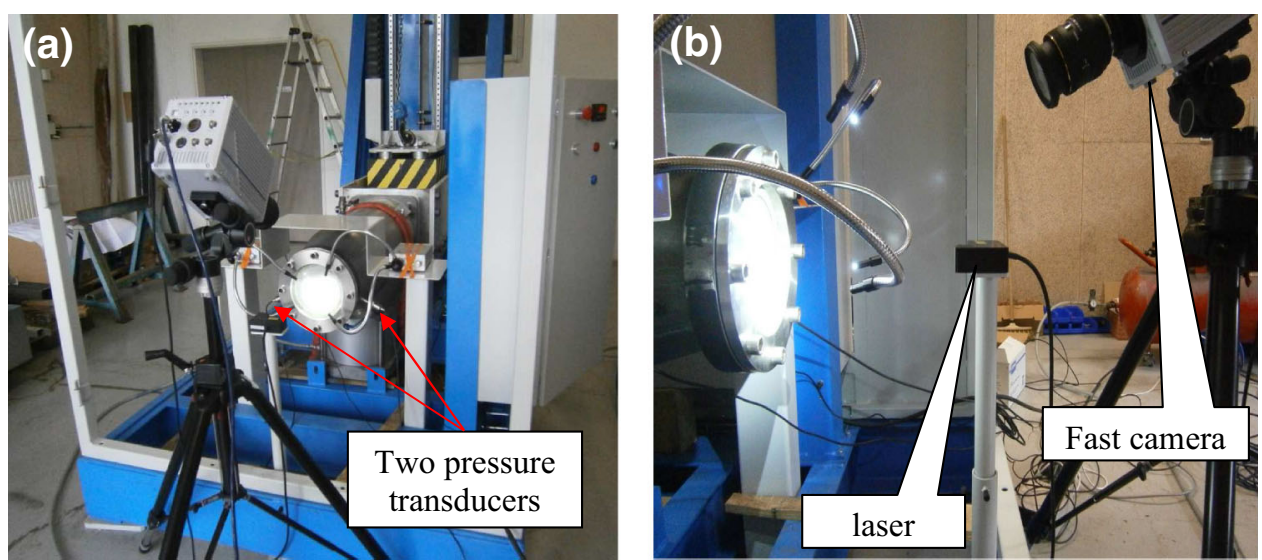
$183.4 \mathrm{~ms}$. The value of $V_{B}$ corresponds to a low velocity impact case $[7,8,13,26]$.

Bringing the deflection at zero, the plate presents a damped vibration and its vibratory movement takes the following form of Eq. (3):

$x(t)=C e^{-\delta t} \sin \left(w_{d} t+\varphi\right)$

where $C e^{-\delta t}$ is the decreased amplitude of $x(t), t$ is the time, $\delta$ is a damping factor and $w_{d}$ is the pulsation of damped oscillations. According to Eq. (3), $x(t)$ tends to 0 as $t$ increases. The deflection at the pole $x(t)$ oscillates between $-C e^{-\delta t}$ and $C e^{-\delta t}$. The two exponential represent the envelope of movement of the composite plate, i.e. the extreme positions taken by $x$ when time elapses (Fig. 8). The identification of the parameters of Eq. (3) is performed by the least squares method by minimizing the error with the experimental response in deflection measured at the center of the plate. The identified parameters are summarized in Table 6 and reported in Fig. 8.

Figure 9 presents the evolution of the crash pressure (for the right and left transducers) versus the measured height at the pole of the plate during the first $5 \mathrm{~ms}$. Considering the effects of inertia in fast dynamic [28], the two curves show some oscillations. However, they have the same variation from 0 to $12.55 \mathrm{~mm}$, which gives the same polynomial regressions $\left(y_{1}\right.$ and $\left.y_{2}\right)$.

With the exception of the dynamic effect (presence of oscillations), the curves of Fig. 9 are similar to those obtained by hydroforming process widely described in literature [29-32]. Hydroforming process, as an advanced manufacturing method, employs the high pressure hydraulic fluid to shape the materials. Generally, there are three classifications to describe the hydroforming: the sheet

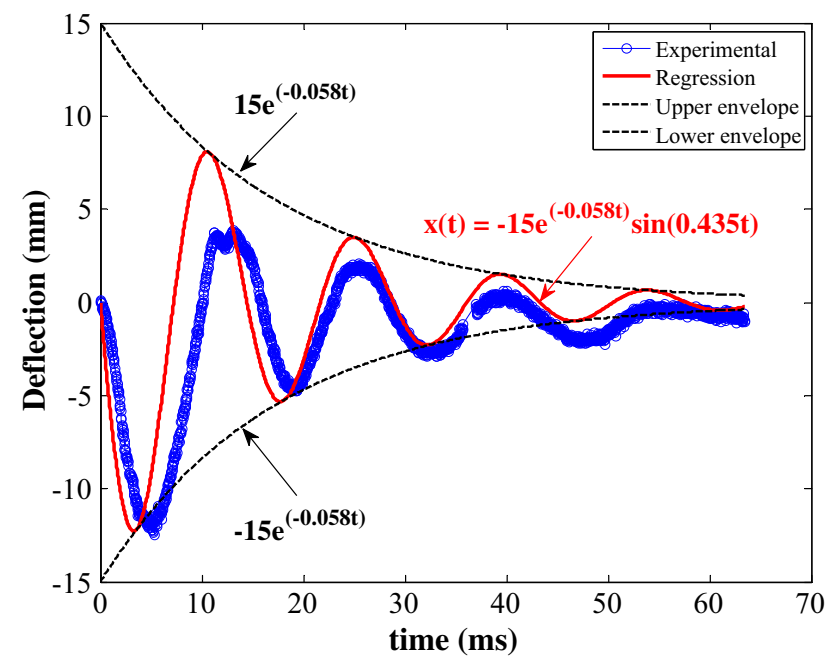

Fig. 8 Damped vibratory movement of PA11/glass fibers composite pate during a hydraulic crash tes conducted at ten bars by the new machine
Table 6 Identified parameters of Eq. (3), vibratory movement of PA11/glass fibers composite plate

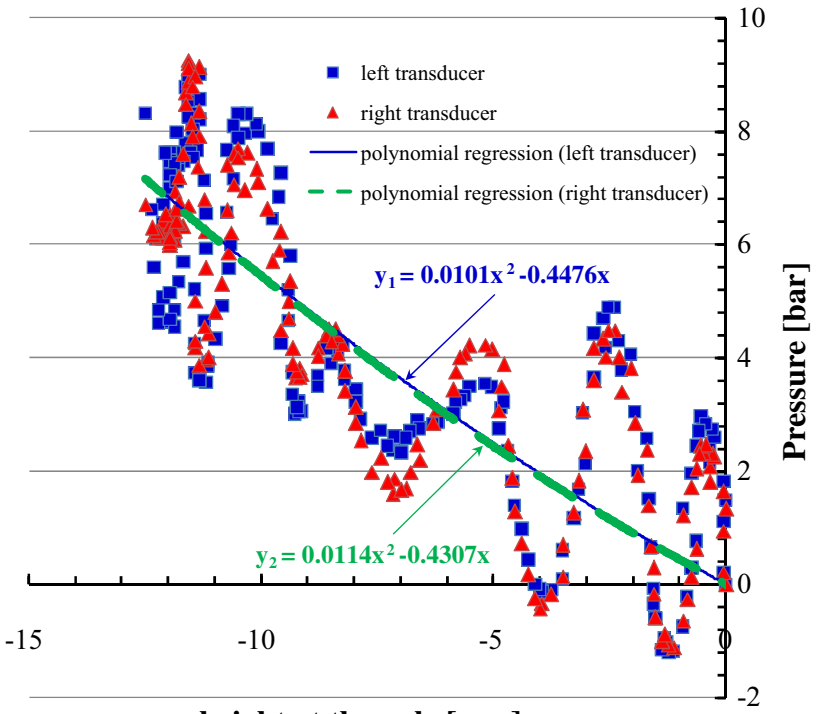

height at the pole $[\mathrm{mm}]$

Fig. 9 Variation of the pressure versus the height at the pole

hydroforming, the tube hydroforming and the internal hydro-bulging. Sheet and tube hydroforming have been widely used in the automotive and aerospace industries, which can be used to produce stronger, lighter and costeffective parts than traditionally made parts.

\section{Numerical Simulation}

In order to predict the dynamic response of PA11/glass fibers composite plate during the first $5 \mathrm{~ms}$ (pressure rise step), the linear explicit dynamic finite element code ABAQUS, version 6.12, was used to simulate the hydraulic crash test by water conducted at ten bars during $5 \mathrm{~ms}$. The orthotropic compliance of composite material has been described by the engineering constants illustrated in Table 4 (the generalized Young's moduli in the principal directions $\mathrm{E}_{1}, \mathrm{E}_{2}, \mathrm{E}_{3}$; the Poisson's ratios in the principal directions $v_{12}, v_{13}, v_{23}$; and the shear moduli in the principal directions $\mathrm{G}_{12}, \mathrm{G}_{13}, \mathrm{G}_{23}$ ). The values of Table 4 are average values obtained after a static mechanical characterization carried out on specimens cut on PA11/glass fibers plates. The tested material has a quasi transverse isotropic symmetry (tetragonal system), i.e. invariant under a rotation of $90^{\circ}$ around a single axis of the principle 
material coordinate system. The twill woven glass fabric used for the manufacture of the thermoplastic composite plate is equilibrated towards in warp (1) and weft (3) directions (Fig. 3). The 2-axis is perpendicular to the plane of the layer and thus also perpendicular to the fibers. For this reason, the extensional moduli of elasticity along the 1 and 3 directions $\left(E_{1}\right.$ and $\left.E_{3}\right)$, the Poisson's ratios $\left(v_{12}\right.$ and $\left.v_{23}\right)$ and the shear moduli $\left(G_{12}\right.$ and $\left.G_{23}\right)$ are equal. Similarly, isotropic behavior of the elastomeric membrane is defined by using the isotropic elastic properties in Table 5 . In Fig. 10, the composite and elastomeric specimens are separated by a sealing gasket (separating seal) with a thickness of $3 \mathrm{~mm}$. Two rigid metallic supports model respectively the end of the metal enclosure and the mechanical flange used for fixing and clamping the specimens. A linear crash pressure from 0 to 10 bars is applied on the flexible elastomeric membrane during one step of $5 \mathrm{~ms}$ (pressure rise phase shown in Fig. 4). The finite element models for composite specimen, elastomeric membrane, sealing gasket and metallic supports were constructed and meshed with Q4 elements to model the crash test, as shown in Fig. 10. As the model is axisymmetric, only a half of the plate is represented in $3 \mathrm{D}$, this facilitates its understanding. The mesh has been optimized until obtaining a stable result of the measured deflection in the center of the upper surface of the composite specimen at $5 \mathrm{~ms}$. Table 7 and Fig. 11a, b illustrate the study of the mesh stability. The displacement $U_{2}$ becomes stable from an approximate element size equal to one which corresponds to 345 Q4 elements. The computation time with ABAQUS software in explicit dynamic step lasts $602 \mathrm{~s}$. The isovalues of displacement field along the $\mathrm{Y}$-axis $\left(\mathrm{U}_{2}\right)$,

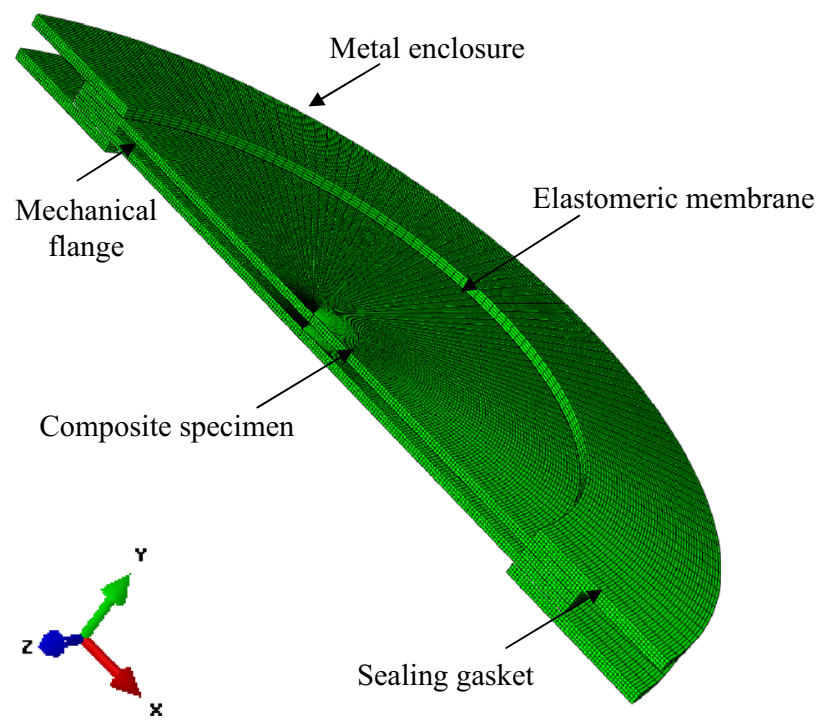

Fig. 10 Different parts constructed the numerical model of the crash test at $5 \mathrm{~ms}$ and at each node of both specimens, are shown in Fig. 12.

A representation in the $(\mathrm{XY})$ plane is proposed in Fig. 13a and the variation of the deflection in the center of the composite plate (identified by the red color node in Fig. 13a) evaluated by the numerical model at the external surface is plotted in Fig. $13 \mathrm{~b}$ versus time. The curve obtained by the dynamic computation (dashed blue line with circles) exhibits oscillations which are due to inertial effects. This finding is largely encountered in dynamic problems like impact tests [28]. For this reason, we proposed to present the numerical deflection by its polynomial regression (continuous blue line). This latter evolves from 0 to $8.8 \mathrm{~mm}$ at $5 \mathrm{~ms}$. To compare, the experimental deflection is presented in purple line with squares. The gap observed between the two curves can be explained by three reasons. Firstly, the crash pressure in numerical model was applied linearly from 0 to 10 bars but it is not the case in the experimental configuration where Fig. 6 proves that the crash pressure raise during the first $5 \mathrm{~ms}$ presents significant fluctuations due to shock waves. Secondly, in the experimental test, although the separating seal was used between the composite specimen and the elastomeric membrane, the air gap of $3 \mathrm{~mm}$ is not guaranteed because the elastomeric membrane is very flexible; contrariwise this condition was respected in numerical simulation. This explains why the numerical deflection at the pole remains null for $0.6 \mathrm{~ms}$, it is the required time to deform the elastomeric membrane. Finally, at a solicitation rate of $2.28 \mathrm{~m} /$ $\mathrm{s}$ the composite plate surely presents a viscoelastic behavior and not a purely elastic behavior as was already used during this numerical simulation. This requires the characterization of PA11/glass fibers composite material at $2.28 \mathrm{~m} / \mathrm{s}$. These factors are hugely important in predicting the dynamic response of the structure.

Through the numerical model, we can evaluate the stress field during the crash pressure raise phase at the red color node (Fig. 13a). Based on the same orthogonal reference, Fig. 14 shows the variations of the radial stress $S_{11}$ (along $\mathrm{X}$-axis), the normal stress $\mathrm{S}_{22}$ (along $\mathrm{Y}$-axis), the revolution stress $S_{33}$ (Z-axis) and the shear stress $S_{12} \cdot S_{11}$ and $S_{33}$ are referred to the blue colored y-axis (left side) while $S_{22}$ and $S_{12}$ are referred to the red colored $y$-axis (right side). All component of the stress tensor are null from 0 to $0.6 \mathrm{~ms}$ because the elastomeric membrane during this time is not still in contact with the composite plate. $S_{11}$ and $S_{33}$ are equal because the glass twill $2 / 2$ woven fabric reinforced composite plate is equilibrated. These two components increase versus time but don't reach the Yield stress $(287 \mathrm{MPa})$. From 0.6 to $1.2 \mathrm{~ms}, \mathrm{~S}_{22}$ evolves in tensile (mainly with positive values), while from $1.2 \mathrm{~ms}$ it becomes a pure compressive stress (negative values) since $\mathrm{S}_{12}$ becomes almost zero. $\mathrm{S}_{22}$ and $\mathrm{S}_{12}$ are too low compared 
Table 7 Mesh stability

\begin{tabular}{lcl}
\hline $\begin{array}{l}\text { Element } \\
\text { size }(\mathrm{mm})\end{array}$ & $\begin{array}{l}\text { Q4 elements } \\
\text { number }\end{array}$ & $\begin{array}{l}\text { Displacement } \mathrm{U}_{2} \\
\text { at } 5 \mathrm{~ms}(\mathrm{~mm})\end{array}$ \\
\hline 2.5 & 46 & -12.447 \\
2 & 116 & -11.878 \\
1.5 & 154 & -11.818 \\
1 & 345 & -10.086 \\
0.5 & 1308 & -10.073 \\
0.4 & 2304 & -10.061 \\
\hline
\end{tabular}
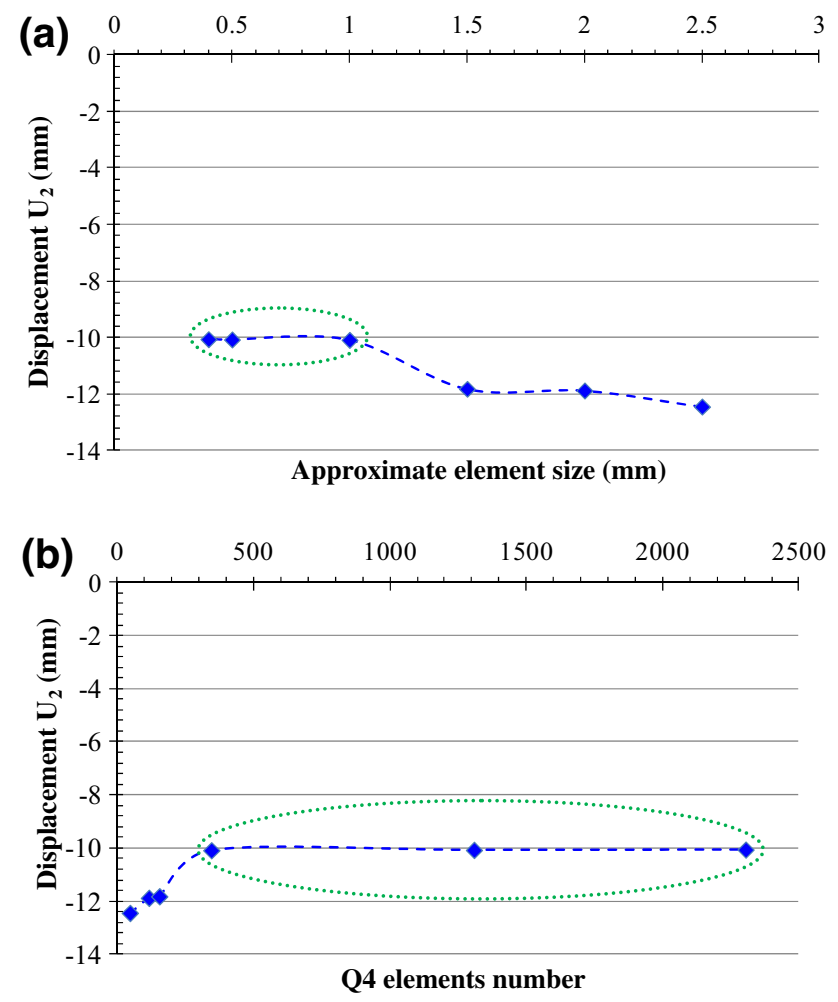

Fig. 11 Mesh study: displacement $U_{2}$ versus approximate element size (a), displacement $\mathrm{U}_{2}$ versus $\mathrm{Q} 4$ elements number (b)

to $S_{11}$ and $S_{33}$ because the thickness of the plate $(3 \mathrm{~mm})$ is small compared to its radius $(115 \mathrm{~mm})$.

\section{Conclusions}

In this study, a new innovative hydraulic crash machine has been used to study the dynamic behavior of thermoplastic composite plates due to a shock conducted by water at ten bars during a period of $10 \mathrm{~ms}$. The crash velocity used in this study is of $3.6 \mathrm{~m} / \mathrm{s}$, thus this machine can be classified in the group of low velocity impact.

It has been instrumented by a fast camera and a laser system for filming and measuring the deflection in the center of composite plate. Two pressure transducers, one in

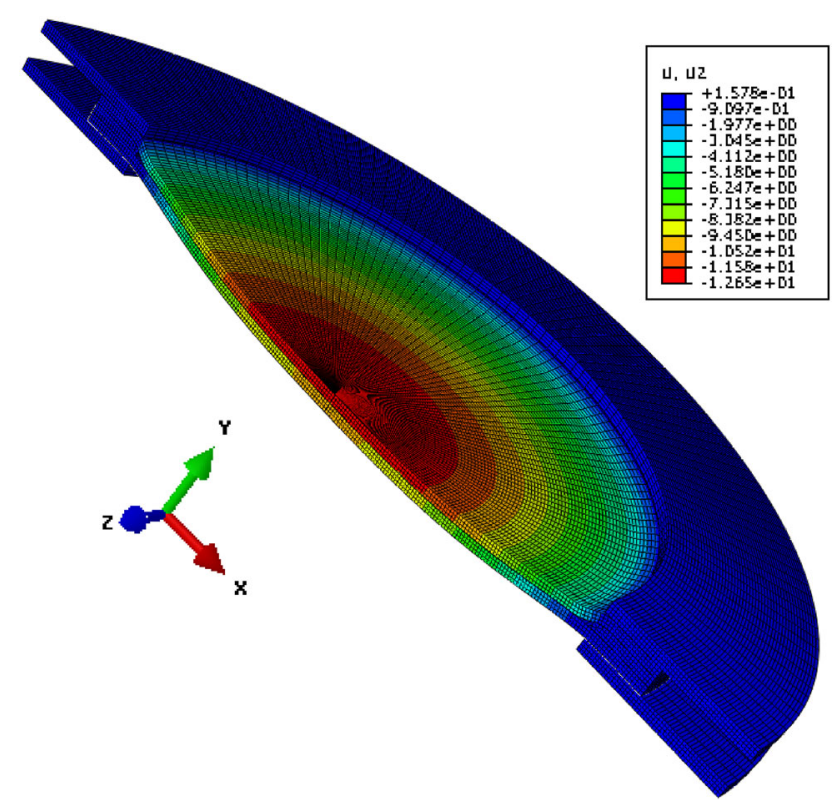

Fig. 12 Isovalues of displacement field $\mathrm{U}_{2}$
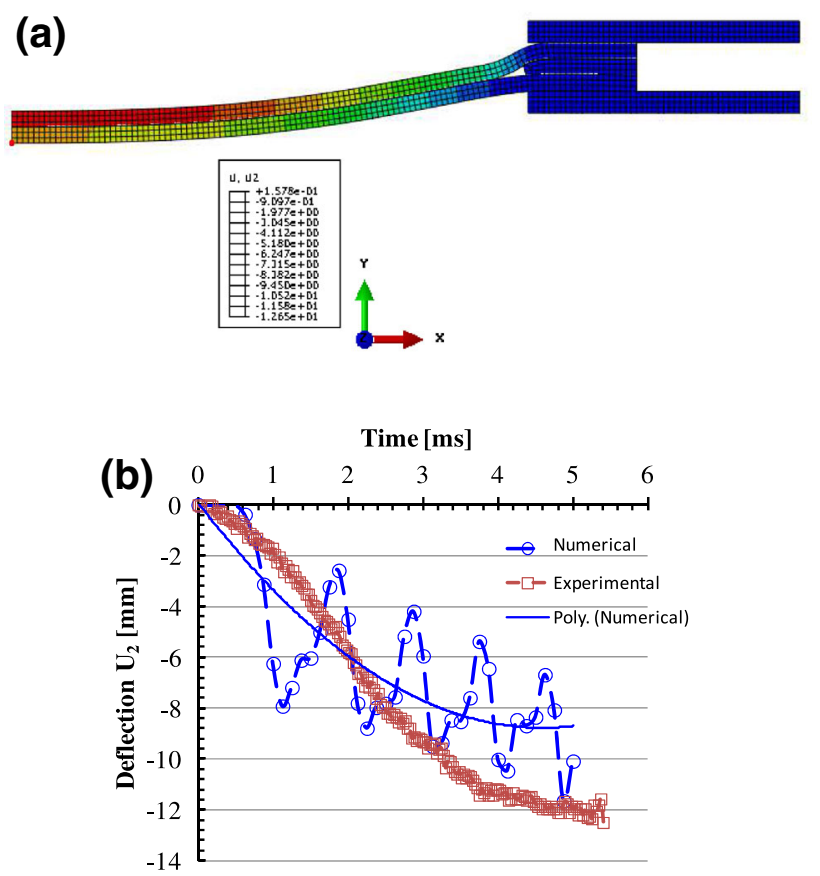

Fig. 13 A representation in the $(X Y)$ plane of displacement field $U_{2}$ (a), comparison beween numerical and experimental deflection measured at the pole of the composite plate (b)

the right and another in the left of the metal enclosure, are used to measure the crash pressure during the hydraulic crash test. The two sensors are faithful and exhibit the same variation of pressure with a presence of fluctuations caused by shock waves. According to its "spring" effect, the plate deforms in a positive and negative senses (tensile/compressive phases). The measured deflection at the pole 


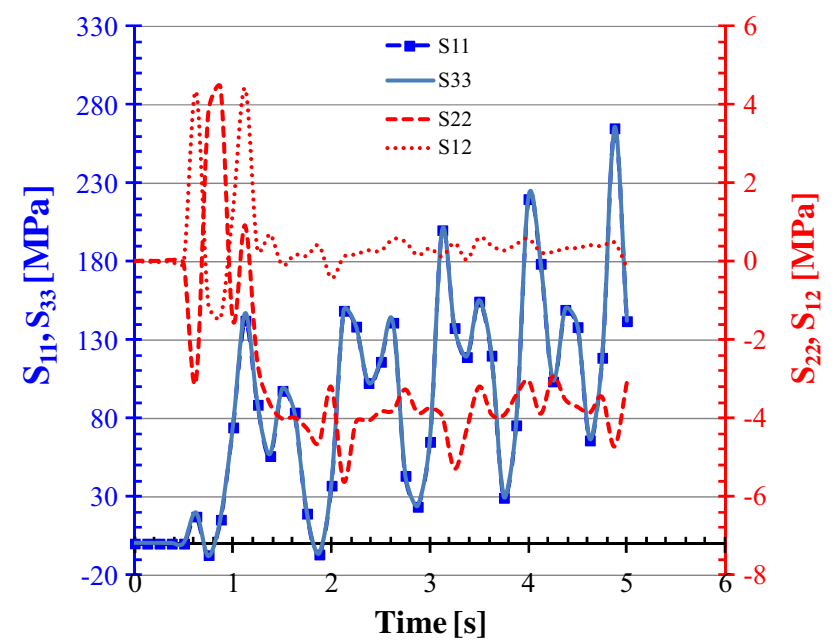

Fig. 14 Variation of stresses field at the center of composite plate on its external face during the crash pressure rise

oscillates and presents a damped vibratory movement. A vibratory model was established and its parameters were identified by regression of the experimental deflection.

A FE simulation with ABAQUS code has been proposed for predicting the dynamic behavior of PMC plates during the pressure rise phase of a proposed hydraulic crash cycle. Numerical deflection at the pole is compared with experimental result to better constrain the model used in ABAQUS. A discrepancy was found between the two curves and some indications have been proposed to explain this finding. However, the stresses field are evaluated and investigated during the first $5 \mathrm{~ms}$.

The obtained results show a very interesting potential of this machine for studying the dynamic behavior of composite structures under low-velocity impact test. The study will be continued according to two main research themes. The first one is experimental for trying to determine an outof-plane strain field of the entire useful diameter which requires the use of two fast cameras (stereo-correlation method). While the second theme addresses the numerical simulation for predicting the real dynamic behavior of the composite plate during the whole time of the hydraulic crash cycle using a viscoelastic mechanical behavior.

Acknowledgments The authors would like to thank the Picardie region, France, patron of "ESCOTHp" Project which financed the research presented in this paper. Also, our acknowledgments are addressed to the different partners of this study: Mines Douai School, Ensait School, MS Composites Company and Zodiac Aerospace Group (France).

\section{References}

1. Colombo C, Vergani L, Burman M (2012) Static and fatigue characterization of new basalt fibre reinforced composites. Compos Struct 94:1165-1174
2. Harizi W, Chaki S, Bourse G, Ourak M (2014) Mechanical damage assessment of glass fiber-reinforced polymer composites using passive infrared thermography. Compos Part B 59:74-79

3. Harizi W, Chaki S, Bourse G, Ourak M (2014) Mechanical damage assessment of polymer-matrix composites using active infrared thermography. Compos B 66:204-209

4. Harizi W, Chaki S, Bourse G, Ourak M (2015) Mechanical damage characterization of glass fiber-reinforced polymer laminates by ultrasonic maps. Compos B 70(1):131-137

5. Al-Haik MS, Hussaini MY, Garmestani H (2006) Prediction of nonlinear viscoelastic behavior of polymeric composites using an artificial neural network. Int J Plast 22:1367-1392

6. Harizi W, Chaki S, Bourse G, Ourak M (2012) Characterization of the damage mechanisms in polymer composite materials by ultrasonic waves, acoustic emission and infrared thermography. In: ECCM15-15th European conference on composite materials, Venice, Italy, 24-28 June 2012

7. Vieille B, Casado VM, Bouvet C (2013) About the impact behavior of woven-ply carbon fiber-reinforced thermoplastic- and thermosetting-composites: a comparative study. Compos Struct 101:9-21

8. Vieille B, Casado VM, Bouvet C (2014) Influence of matrix toughness and ductility on the compression-after-impact behavior of woven-ply thermoplastic- and thermosetting-composites: a comparative study. Compos Struct 110:207-218

9. Cantwell WJ, Morton J (1991) The impact resistance of composite materials-a review. Composites 22(5):347-362

10. Jang BP, Kowbel W, Jang BZ (1992) Impact behavior and impact-fatigue testing of polymer composites. Compos Sci Technol 44(2):107-118

11. Abrate S (1998) Impact on composites structures. Cambridge University Press, Cambridge

12. Hancox NL (2000) An overview of the impact behavior of fibrereinforced composites. In: Reid SR, Zhou G (eds) Impact behavior of fiber-reinforced composite materials and structures. CRC Press, Woodhead Pub.Ltd, Cambridge

13. Lascoup B, Aboura Z, Khellil K, Benzeggagh M (2010) Impact response of three-dimensional stitched sandwich composite. Compos Struct 92:347-353

14. Siewert TA, Manahan MP Sr (eds) (2000) Pendulum impact testing: a century of progress. STP 1380. American Society for Testing and Materials, West Conshohocken

15. ASTM E23-07 (2007) Standard test methods for determining the notched bar impact testing of metallic materials. American Society for Testing and Materials, West Conshohocken

16. ASTM D256-10 (2010) Standard test methods for determining the Izod pendulum impact resistance of plastics. American Society for Testing and Materials, West Conshohocken

17. ASTM D6110-10 (2010) Standard test methods for determining the Charpy impact resistance of notched specimens of plastics. American Society for Testing and Materials, West Conshohocken

18. ASTM D7136, D7136M-12 (2012) Standard test method for measuring the damage resistance of a fiber-reinforced polymer matrix composite to a drop-weight impact event. American Society for Testing and Materials, West Conshohocken

19. Small MK, Nix WD (1992) Analysis of the accuracy of the bulge test in determining the mechanical properties of thin films. J Mater Res 7:1553-1563

20. Bonnotte E, Delobelle P, Bornier L, Trolard B, Tribillon G (1997) Two interferometric methods for the mechanical characterization of thin films by bulging tests. Application to silicon single crystal. J Mater Res 12:2234-2248

21. Basrour S, Robert L, Delobelle P (2000) Measurement of residual stresses in a plate using bulging test and a dynamic technique: application to electroplated nickel coatings. Mater Sci Eng A 288:160-163 
22. Meyers MA (1994) Dynamic behavior of materials. Wiley, New York

23. Chen W, Song B (2010) Split Hopkinson (Kolsky) bar design, testing and applications. Springer, New York

24. Ravi-Chandar K (2004) Dynamic fracture. Elsevier, Amsterdam

25. Kulin RM, Jiang F, Vecchio KS (2011) Effects of age and loading rate on equine cortical bone failure. $J$ Mech Behav Biomed Mater 4:57-75

26. Haugou G, Fabis J, Langrand B, Deletombe E, Markiewicz E (2002) Iterative experimental/numerical procedure for improvement of dynamic experimental facilities. In: Structure Under Shock and Impact VII (SUSI2002), Montreal, 27-29 May 2002

27. Harizi W, Kaidi S, Monnin A, El Hajj N, Aboura Z, Benzeggagh $M$ (2015) A new hydraulic crash machine for composite structures. J Dyn Behav Mater. 1(1):101
28. Bonnet B (2005) Comportement au choc de matériaux composites pour applications automobiles. Mechanics. Ecole Nationale Supérieure des Mines de Paris

29. Zhang Q, Wang ZR (2015) Shape improvement of a dieless hydro-bulged sphere made of hexagonal and pentagonal shaped panels. J Mater Process Technol. doi:10.1016/j.jmatprotec.2015. 01.012

30. Lang LH, Wang ZR, Kang DC, Yuan SJ, Zhang SH, Danckert J, Nielsen KB (2004) Hydroforming highlights: sheet hydroforming and tube hydroforming. J Mater Process Technol 151:165-177

31. Velasco R, Boudeau N (2008) Tube bulging test: theoretical analysis and numerical validation. J Mater Process Technol 205:51-59

32. Abedrabbo N, Mayer R, Thompson A, Salisbury C, Worswick M, van Riemsdijk I (2009) Crash response of advanced high-strength steel tubes: experiment and model. Int J Impact Eng 36:1044-1057 